\title{
Methicillin-Resistant Staphylococcus aureus in Raw Milk: Prevalence, SCCmec Typing, Enterotoxin Characterization, and Antimicrobial Resistance Patterns
}

\author{
ALESSANDRA RIVA, ${ }^{1}$ ELISA BORGHI, ${ }^{1 *}$ DANIELA CIRASOLA,${ }^{1}$ SILVIA COLMEGNA,${ }^{2}$ FRANCESCA BORGO,${ }^{1}$ \\ ETTORE AMATO,${ }^{1}$ MIRELLA MARIA PONTELLO,${ }^{1}$ AND GIULIA MORACE ${ }^{1}$ \\ ${ }^{1}$ Department of Health Sciences, Università degli Studi di Milano, Via di Rudinì 8, 20142 Milan, Italy; and ${ }^{2}$ Istituto Zooprofilattico della Lombardia e \\ dell'Emilia Romagna, Via Celoria 12, 20133 Milan, Italy
}

MS 14-531: Received 12 November 2014/Accepted 30 January 2015

\begin{abstract}
Staphylococcus aureus is a known major cause of foodborne illnesses, and raw milk and dairy products are often contaminated by enterotoxigenic and antimicrobial-resistant $S$. aureus strains. In the present study, 35 S. aureus strains were isolated from 383 raw milk samples collected from various dairy herds in the province of Milan (northern Italy). The isolates were characterized based on their antimicrobial susceptibility patterns and the presence of genes encoding staphylococcal enterotoxins (sea, seb, sec, sed, and see). About half (45.7\%) of the strains were enterotoxigenic, and $37.1 \%$ were resistant to at least one of the antimicrobial drugs tested. Seven (20\%) of 35 isolates were identified as methicillin-resistant S. aureus (MRSA), and SCCmec typing performed with a multiplex PCR assay revealed the presence of gene cassettes IV and V, typical of communityacquired MRSA, and I and II, characteristic of health care-associated MRSA. The MRSA strains were evaluated for the presence of the Panton-Valentine leukocidin gene, but this gene was not found. The results of the present study revealed the presence of toxin-producing S. aureus and MRSA strains in raw milk. MRSA and enterotoxigenic S. aureus in dairy farms are an important risk factor for the spread of staphylococcal infections; therefore, further studies are needed to find strategies for monitoring and controlling the presence of $S$. aureus, especially MRSA, in dairy products.
\end{abstract}

Staphylococcus aureus can cause a wide spectrum of diseases in both humans and animals. In humans, staphylococcal infections are frequently reported and can be contracted inside or outside of a health care setting (33). An important public health issue concerning staphylococcal infections is the development of drug resistance due to the intensive use of antimicrobials in human and veterinary medicine $(12,36)$. Methicillin-resistant Staphylococcus aureus (MRSA) strains are one of the most important causes of health care-associated infections worldwide $(11,12)$. MRSA was first described in 1961 (18), soon after the introduction of methicillin. Methicillin resistance is due to the acquisition of the mecA gene, which encodes a penicillin-binding protein (PBP2a) with a low affinity for $\beta$-lactams. mecA is located on a mobile genetic element called staphylococcal cassette chromosome mec (SCCmec). Currently, 11 main types of SCCmec (I through XI) are recognized (16). SCCmec types I, IV, V, VI, and VII usually cause only $\beta$-lactams antibiotic resistance, but SCCmec types II and III harbor resistance to multiple classes of antibiotics because of the additional drug resistance genes integrated into SCCmec as plasmids and transposons. MRSA strains are often associated with hospital infections and are defined as hospital-acquired (HA) MRSA,

\footnotetext{
* Author for correspondence. Tel: +39-02-50323240; Fax: +39-0250323287; E-mail: elisa.borghi@unimi.it.
}

but recently MRSA have been increasingly detected in community (community-acquired [CA] MRSA) and in farm (livestock-associated [LA] MRSA) environments (10, 12, 27). CA-MRSA strains are predominantly characterized by SCCmec types IV or V, whereas HA-MRSA strains are characterized by SCCmec types I, II, and III (10). Some CAMRSA strains express the Panton-Valentine leukocidin (PVL), a cytotoxin that causes leucocyte destruction and tissue necrosis (4). PVL is widely associated with the presence of SCCmec type IV (6).

$S$. aureus is one of the most common foodborne pathogens and is among the leading causes of foodborne outbreaks worldwide $(33,34,37)$. The European Food Safety Authority and the European Centre for Disease Prevention and Control (13) reported 346 outbreaks caused by staphylococcal enterotoxins (SEs), representing $6.4 \%$ of all outbreaks detected in Europe in 2012. Staphylococcal foodborne poisoning is caused by the ingestion of food containing SEs. Symptoms include nausea, vomiting, abdominal cramps, and diarrhea (37). The classical antigenic-based classification of SEs includes five serological types: SEA, SEB, SEC, SED, and SEE. In recent years, new types of SE and SE-like toxins (SEG, SEH, SEI, SEIJ, SEIK, SEIL, SEIM, SEIN, SEIO, SEIP, SEIQ, SEIR, and SEIU) have been reported. These new toxins have been identified based on their sequence similarity with classical SEs, but their emetic properties are still unknown (32). 
SEs are highly thermostable and resistant to many proteolytic enzymes and different environmental conditions. The most common SE associated with foodborne illness is SEA (33). Although pasteurization eliminates staphylococci, it has no effect on SEs. Raw milk, subjected only to filtration, and other unpasteurized dairy products may contain enterotoxigenic $S$. aureus strains (23).

In general, $S$. aureus can enter milk either by direct excretion from the udder of a cow with clinical and subclinical staphylococcal mastitis or by contamination from the environment during handling and processing of raw milk. Raw milk is a vehicle for the transmission of numerous bacteria of human and animal origin and represents a public health hazard (23).

The aim of this study was to assess the presence of $S$. aureus strains in raw milk, to characterize the isolates by testing their antimicrobial susceptibility, to determine the SCCmec type in MRSA isolates, and assess the enterotoxigenic activity of raw milk isolates from northern Italy.

\section{MATERIALS AND METHODS}

Samples collection and culture. The 383 raw milk samples were collected from dairy herds between April and October 2012 during a regional monitoring program at the Istituto Zooprofilattico Sperimentale della Lombardia e dell'Emilia Romagna (IZSLER, Milan section). Samplings were obtained from bulk tank milk (282 samples) and vending machines (101 samples) in the provinces of Milan and Monza-Brianza, northern Italy.

Raw milk samples were collected from farms and transported to the laboratory at a controlled temperature $\left(4^{\circ} \mathrm{C}\right)$. Samples were analyzed according to method UNI EN ISO:6888-2:199935 (17). Diluted and undiluted samples (1 ml each) were plated on BairdParker agar supplemented with rabbit plasma fibrinogen (IZSLER, Brescia section) and incubated at $37^{\circ} \mathrm{C}$ for 18 to $24 \mathrm{~h}$ under aerobic conditions. Typical black colonies with an opaque halo were picked from plates and subcultured on nutrient agar (Difco, BBL, $\mathrm{BD}$, Lawrence, KS). Five isolated colonies from each plate were subjected to catalase and coagulase plasma EDTA test (Biolife, Milan, Italy) for presumptive identification of S. aureus. S. aureus ATCC 25923 and Staphylococcus epidermidis ATCC 12228 were used as positive and negative controls, respectively.

Only unduplicated $S$. aureus strains isolated from raw milk samples were further investigated for general antibiotic resistance, enterotoxin production, methicillin resistance, and SSCmec types at the Department of Health Science of the Università degli Studi di Milano (Milan, Italy).

Antimicrobial susceptibility testing. Antimicrobial susceptibility testing was performed using the Kirby-Bauer diffusion method $(1,7)$ and the following disks: $30 \mu \mathrm{g}$ of tetracycline (Te), $25 \mu \mathrm{g}$ of sulfamethoxazole-trimethoprim (Stx), $30 \mu \mathrm{g}$ of chloramphenicol $(\mathrm{C}), 5 \mu \mathrm{g}$ of ciprofloxacin, $10 \mu \mathrm{g}$ of gentamicin $(\mathrm{Gm})$, $10 \mu \mathrm{g}$ of penicillin $(\mathrm{Pe}), 15 \mu \mathrm{g}$ of erythromycin $(\mathrm{E})$, and $25 \mu \mathrm{g}$ of clindamycin $(\mathrm{Cm})$ (BioRad, Marnes-la-Coquette, France) on Mueller-Hinton agar (Oxoid, Basingstoke, UK). The zones of inhibition were measured in millimeters, and strains were defined as susceptible or resistant according to established interpretive breakpoints (8). To detect methicillin resistance, a 5 - $\mu$ g oxacillin (Ox) disk was used (8). Inducible macrolide-lincosaminestreptogramin B resistance was verified by the D test (40). Isolates were considered multidrug resistant when three or more different drug classes were ineffective.
DNA extraction and molecular typing. $S$. aureus strains were cultured on tryptic soy agar (Oxoid) at $37^{\circ} \mathrm{C}$ for $24 \mathrm{~h}$, and DNA was extracted using Prepman Ultra Reagent (Applied Biosystem, Foster City, CA). The extracted DNA was quantified by spectrophotometer (BioRad) and stored at $-20^{\circ} \mathrm{C}$ until used.

All MRSA isolates were submitted to a multiplex PCR for detection of the SSCmec types implicated in drug resistance (5). The presence of the PVL gene was detected by PCR as described by Lina et al (25). The amplicons were subjected to electrophoresis in a $2 \%$ agarose gel and stained with ethidium bromide. All PCRs included positive controls. The presence of the genes that encode for SEA through SEE was detected by two different multiplex PCRs, according to the protocol described by Mehrotra et al. (28). The first was conducted for sed and see, and the second was conducted for sea, seb, and sec. As an internal positive control, specific primers to amplify femA were incorporated. All PCR products were analyzed by $1.5 \%$ agarose gel electrophoresis and visualized under UV light.

Statistical analysis. Results were expressed as numbers for categorical variables. Associations between categorical variables were assessed using the chi-square test or the Fisher exact test as appropriate. Statistical analysis was performed using Epi-Info 3.5 software (Centers for Disease Control and Prevention, Atlanta, GA). Differences were considered significant at $P<0.05$.

\section{RESULTS}

S. aureus isolates were recovered from $35(9.1 \%)$ of the 383 raw milk samples from dairy farms, i.e., from 30 $(10.6 \%)$ of 282 bulk tank milk samples and from 5 (4.9\%) of 101 vending machines samples collected as part of a regional monitoring program in the province of Milan from April to October 2012.

The majority of the isolates $(62.8 \%)$ were susceptible to all the antibacterial drugs tested; the remaining 13 (37.1\%) were resistant to penicillin. Among these isolates, five were multidrug resistant and seven $(1.8 \%)$, including four that were multidrug resistant, were classified as methicillin resistant by the Ox test (Table 1). No difference was noted with respect to the origin of the MRSA-positive samples; $1.7 \%$ (5 of 282) were from bulk tank milk and 1.9\% (2 of 101) were from vending machines.

All S. aureus strains were negative with the D test, indicating no resistance to macrolide-lincosamine-streptogramin B.

The characterization of the SCCmec genes by multiplex PCR allowed classification of the seven MRSA strains into four types. Three strains harbored the SCCmec type IV cassette, two strains had type $\mathrm{V}$, one strain had type I, and one strain had type II (Table 1). None of the MRSA strains harbored the gene encoding PVL.

The presence of enterotoxigenic strains was detected by multiplex PCR. Sixteen $(45.7 \%)$ of the 35 isolates harbored at least one gene encoding SEs; 4.6\% (13 of 282) of the toxigenic strains came from bulk tank milk, and 3\% (3 of 101) came from vending machines. The majority of the enterotoxigenic strains ( 9 of 16) had only one SE gene (7 had sec and 2 had sed), 3 strains (8.5\%) genes for three toxins (sea, sed, and see), and two (5.7\%) had genes for four toxins (sea, seb, sed, and see) (Table 1). 
TABLE 1. Antimicrobial resistance, toxigenic profiles, methicillin resistance, and $\mathrm{SCC} \mathrm{mec}$ gene cassettes in $\mathrm{S}$. aureus isolates from raw milk samples in northern Italy

\begin{tabular}{|c|c|c|c|c|}
\hline $\begin{array}{c}\text { Isolate } \\
\text { no. }\end{array}$ & $\begin{array}{l}\text { Sample } \\
\text { source }^{a}\end{array}$ & $\begin{array}{l}\text { Enterotoxin } \\
\text { gene }(\mathrm{s})^{b}\end{array}$ & Resistance pattern ${ }^{c}$ & $\begin{array}{l}\text { SCCmec } \\
\text { type }^{d}\end{array}$ \\
\hline 1 & V & $\sec$ & & \\
\hline 2 & V & $\sec$ & & \\
\hline 5 & $\mathrm{~T}$ & & $\mathrm{Cm}, \mathrm{E}, \mathrm{Pe}$ & \\
\hline 7 & $\mathrm{~T}$ & $\sec$ & $\mathrm{Pe}, \mathrm{Te}$ & \\
\hline 8 & $\mathrm{~T}$ & & $\mathrm{Pe}$ & \\
\hline 14 & $\mathrm{~T}$ & $\sec$ & $\mathrm{Pe}, \mathrm{Te}$ & \\
\hline 15 & $\mathrm{~T}$ & $\mathrm{sec}$ & & \\
\hline 16 & $\mathrm{~T}$ & $\sec$ & & \\
\hline 17 & $\mathrm{~T}$ & $\begin{array}{l}\text { sea, seb, sed, } \\
\text { see }\end{array}$ & & \\
\hline 18 & $\mathrm{~T}$ & sed & $\mathrm{Ox}, \mathrm{Pe}$ & V \\
\hline 21 & $\mathrm{~T}$ & & $\mathrm{Ox}, \mathrm{Pe}, \mathrm{Te}$ & I \\
\hline 22 & $\mathrm{~T}$ & sea, sed, see & $\mathrm{Cm}, \mathrm{E}, \mathrm{Ox}, \mathrm{Pe}, \mathrm{Te}$ & II \\
\hline 23 & $\mathrm{~T}$ & & $\mathrm{C}, \mathrm{Ox}, \mathrm{Pe}, \mathrm{Te}$ & $\mathrm{V}$ \\
\hline 24 & $\mathrm{~T}$ & sed & & \\
\hline 25 & $\mathrm{~T}$ & $\begin{array}{l}\text { sea, seb, sed, } \\
\text { see }\end{array}$ & & \\
\hline 26 & $\mathrm{~T}$ & & & \\
\hline 27 & $\mathrm{~T}$ & & $\mathrm{Ox}, \mathrm{Pe}, \mathrm{Te}$ & IV \\
\hline 29 & $\mathrm{~T}$ & sea, sed, see & & \\
\hline 30 & $\mathrm{~V}$ & & $\mathrm{E}, \mathrm{Gm}, \mathrm{Ox}, \mathrm{Pe}, \mathrm{Sxt}$ & IV \\
\hline 31 & $\mathrm{~V}$ & & E, Gm, Ox, Pe, Sxt & IV \\
\hline 32 & $\mathrm{~T}$ & $\sec$ & $\mathrm{Pe}$ & \\
\hline 34 & $\mathrm{~V}$ & $\sec$ & & \\
\hline 35 & $\mathrm{~T}$ & $\sec$ & $\mathrm{Pe}$ & \\
\hline
\end{tabular}

${ }^{a} \mathrm{~V}$, vending machines; $\mathrm{T}$, bulk milk tanks.

${ }^{b}$ Genes for staphylococcal enterotoxins A (sea), B (seb), C (sec), $\mathrm{D}$ (sed) and $\mathrm{E}(\mathrm{see})$.

${ }^{c} \mathrm{C}$, chloramphenicol; $\mathrm{Cm}$, clindamycin; E, erythromycin; $\mathrm{Gm}$, gentamicin; Ox, oxacillin; Pe, penicillin; Sxt, sulfamethoxazoletrimethoprim; Te, tetracycline.

${ }^{d}$ SCCmec, staphylococcal chromosome cassette for methicillin resistance.

\section{DISCUSSION}

In this study, we isolated $S$. aureus strains from 35 (9.1\%) of the 383 raw milk samples collected in northern Italy. Five strains were multidrug resistant, i.e., resistant to three or more classes of the antibiotics most commonly used in veterinary medicine, and seven (including four multidrugresistant strains) were classified as MRSA.

The detection of antimicrobial-resistant microorganisms in raw milk is a highly important issue for public health because of possible spread of these microorganisms through the dairy food chain. Bovine milk is a significant source of Ox-resistant, mecA-positive strains of S. aureus (27). Although the role of food as a vehicle of human infection by MRSA is currently regarded as secondary, MRSA strains are able to evolve very quickly, and characteristics such as virulence and transmissibility can change (12). Therefore, transmission of MRSA strains from animals to humans and vice versa has the potential to introduce new pathogenic strains into these populations.

The patterns of multidrug resistance observed in the MRSA strains are an additional pathogenic factor and a risk for the spread of isolates able to cause infections that are difficult to treat. Although MRSA is comparatively rare in food, dairy milk might be one of the possible sources of MRSA because of wide use of antimicrobials for the treatment of mammary infections in cattle $(2,22,24)$. The presence of MRSA strains in bovine milk has been reported in various countries, including Italy, Germany, England, and Turkey, and these data are consistent with in the results of the present study $(2,22,35,38)$. Among the $S$. aureus isolates we obtained from bovine milk, 20\% were MRSA, which is comparable to the results reported by Benedetti et al. (2), who found MRSA among $13 \%$ of 413 S. aureus isolates in the province of Lodi, Italy. Similar results were reported in Turkey (38): 17\% of 93 S. aureus isolates were MRSA. The $1.8 \%$ prevalence of MRSA in our samples (7 of 383 samples) is comparable with the $2.3 \%$ prevalence reported in England (35) and Germany (22).

Molecular characterization of the seven MRSA strains revealed SCCmec types IV and V, typical of CA-MRSA, in five of these seven strains; these data are in agreement with current literature $(2,39)$. Two of these strains had SCCmec types I and II, characteristic of HA-MRSA. Gene cassettes typically found in the health care environment have also been found in other studies. In Japan, Hata et al. (14) detected SCCmec types II and III, and in Turkey Türkyılmaz et al. (38) found SCCmec III in $87.5 \%$ of MRSA strains isolated from bovine milk. The detection of SCCmec types IV and V in this study suggests the emergence of CA-MRSA strains in this geographical area, and the presence of SCCmec types I and II might indicate a possible transmission from humans to animals (38). With the exception of one MRSA SCCmec type $\mathrm{V}$, resistant only to $\beta$-lactams, four of the MRSA strains were multidrug resistant, and the other two were also resistant to tetracycline.

A high percentage $(45.7 \%)$ of $S$. aureus strains found in our study harbored the genes that encode for enterotoxins involved in staphylococcal food poisoning. Five strains had a highly toxigenic genotype, encoding for thee or more toxins: two strains harbored sea, seb, sed, and see, and three strains harbored sea, sed, and see. We found the sec gene in $56 \%$ of the toxigenic isolates. This finding corroborates the data obtained by others $(20,26,29,37)$, who reported that SEC was the most common SE produced by $S$. aureus isolates from milk-producing animals. The prevalence of toxigenic $S$. aureus in raw milk in Italy is also important because many typical Italian cheeses, both fresh and seasoned, are produced from unpasteurized milk $(3,9,30$, 31). Differences in the prevalence of toxigenic $S$. aureus strains have been observed among geographical areas. Jørgensen et al. (20) found a $22.1 \%$ prevalence of SEproducing strains in bovine milk in Norway; Zouharova and Rysanek (41) found a $12.9 \%$ prevalence of enterotoxigenic $S$. aureus strains in bulk tank milk in the Czech Republic, and Neder et al. (29) detected $11.7 \%$ prevalence of enterotoxigenic $S$. aureus strains in bulk tank milk in Argentina. These differences in the prevalence of enterotoxin production might be explained by the techniques used in these studies, the origin of the isolates, and the geographical location. 
Only two MRSA isolates harbored the genes coding for SEs; one of these strains harbored SCCmec type II (a multiresistance profile for clindamycin, erythromycin, and tetracycline) and the sea, sed, and see genes. These data are consistent with the reports of foodborne outbreaks caused by MRSA $(19,21)$. None of the MRSA strains isolated in our study harbored the gene for PVL, in agreement with other reports concerning a low number of MRSA strains $(15,35,38)$. Benedetti et al. (2) found only one MRSA isolate with the gene for PVL among 14 MRSA isolates from bovine milk.

No significant difference in the prevalence of $S$. aureus strains was found between samples from bulk milk tanks and those from vending machines. We assume that no secondary contamination occurred during the process of storage and transfer of raw milk or storage of milk for retail sale (cold chain). The lack of a significant difference in the S. aureus results obtained from these two sources (tanks and vending machines) supports the validity of the sampling procedure, which was carried out in parallel.

In conclusion, our data suggest that surveillance and monitoring of $S$. aureus in food of animal origin is needed. MRSA strains in livestock and the correct use of antibiotics should be evaluated and monitored to prevent and limit evolutionary pressure that could favor the spread of antimicrobial-resistant microorganisms.

\section{REFERENCES}

1. Bauer, A. W., W. M. Kirby, J. C. Sherris, and M. Turk. 1996. Antibiotic susceptibility testing by a standardized single disk method. Am. J. Clin. Pathol. 45:493-496.

2. Benedetti, V., P. Cremonesi, S. Ferrari, B. Castigiloni, M. Fabbi, N. Vicari, C. Garbarino, A. Battisti, A. Franco, F. Feltrin, and M. Luini. 2010. Staphylococcus aureus meticillino-reistente (MRSA) da campioni di latte bovino. Large Anim. Rev. 16:67-70.

3. Bianchi, D. M., S. Gallina, A. Bellio, F. Chiesa, T. Civera, and L. Decastelli. 2013. Enterotoxin gene profiles of Staphylococcus aureus isolated from milk and dairy products in Italy. Lett. Appl. Microbiol. 58:190-196.

4. Borghi, E., M. Cainarca, R. Sciota, C. Biassoni, and G. Morace. 2010. Molecular picture of community and healthcare associated methicillin resistant Staphylococcus aureus circulating in a teaching hospital in Milan. Scand. J. Infect. Dis. 42:873-878.

5. Boye, K., M. D. Bartels, I. S. Andersen, J. A. Møller, and H. Westh. 2007. A new multiplex PCR for easy screening of methicillinresistant Staphylococcus aureus SCCmec types I-V. Clin. Microbiol. Infect. 13:725-727.

6. Boyle-Vavra, S., and R. S. Daum. 2007. Community-acquired methicillin-resistant Staphylococcus aureus: the role of PantonValentine leukocidin. Lab. Invest. 87:3-9.

7. Clinical and Laboratory Standards Institute. 2012. Performance standards for antimicrobial disk susceptibility tests; approved standard M02-A11 PK, 11th ed. Clinical and Laboratory Standards Institute, Wayne, PA.

8. Clinical and Laboratory Standards Institute. 2013. Performance standards for antimicrobial disk susceptibility tests; approved standard M100-S23. Clinical and Laboratory Standards Institute, Wayne, PA.

9. Crisetti, E., A. Cataleta, M. D'Alessandro, G. Normanno, D. Chiocco, and G. La Salandra. 2012. Enterotoxigenic and methicillin resistant Staphylococcus aureus (MRSA) in dairy products of Puglia region (Italy)—preliminary data. Ital. J. Food Saf. 1:99-100.

10. De Lencastre, H., D. Oliveira, and A. Tomasz. 2007. Antibiotic resistant Staphylococcus aureus: a paradigm of adaptive power. Curr. Opin. Microbiol. 13:971-979.
11. European Centre for Disease Prevention and Control. 2013. Annual epidemiological report 2013. Reporting on 2011 surveillance data and 2012 epidemic intelligence data. European Centre for Disease Prevention and Control, Stockholm. Available at: http://www.ecdc. europa.eu/en/publications/Publications/annual-epidemiological-report2013.pdf. Accessed March 2015.

12. European Food Safety Authority. 2012. Technical specification on the harmonized monitoring and reporting of antimicrobial resistance in methicillin-resistant Staphylococcus aureus in food-producing animals and food. EFSA J. 10:2897.

13. European Food Safety Authority and European Centre for Disease Prevention and Control. 2014. The European Union summary report on trends and sources of zoonoses, zoonotic agents and food-borne outbreaks in 2012. EFSA J. 12:3547.

14. Hata, E., K. Katsuda, H. Kobayashi, I. Uchida, K. Tanaka, and M. Eguchi. 2010. Genetic variation among Staphylococcus aureus strains from bovine milk and their relevance to methicillin-resistant isolates from humans. J. Clin. Microbiol. 48:2130-2139.

15. Huber. H, S. Koller, N. Giezendanner, R. Stephan, and C. Zweifel. 2010. Prevalence and characteristics of meticillin-resistant Staphylococcus aureus in humans in contact with farm animals, in livestock, and in food of animal origin, Switzerland, 2009. Euro Surveill. 15: $\mathrm{pii}=19542$.

16. International working group on the classification of staphylococcal cassette chromosome elements (IWG-SCC). 2009. Classification of staphylococcal cassette chromosome mec (SCCmec): guidelines for reporting novel SCC mec elements. Antimicrob. Agents Chemother. 53:4961-4967.

17. International Organization for Standardization. 2003. Microbiology of food and animal feeding stuffs-horizontal method for the enumeration of coagulase-positive staphylococci (Staphylococcus aureus and other species). Part 2. Technique using rabbit plasma fibrinogen agar medium. Amendment 1 . Inclusion of precision data. 6888-2:1999/AMD.1:2003. International Organization for Standardization, Geneva.

18. Jevons, M. P. 1961. Celbenin-resistant staphylococci. Br. Med. J. 5219:124-125.

19. Jones, F. T., M. E. Kellum, S. S. Porter, M. Bell, and W. Schaffner. 2002. An outbreak of community-acquired foodborne illness caused by methicillin resistant Staphylococcus aureus. Emerg. Infect. Dis. 8:82-84.

20. Jørgensen, H. J., T. Mørk, H. R. Høgåsen, and L. M. Rørvik. 2005. Enterotoxigenic Staphylococcus aureus in bulk milk in Norway. $J$. Appl. Microbiol. 99:158-166.

21. Kluytmans, J., W. Van Leeuwen, W. Goessen, R. Hollin, S. Messer, L. Herwaldt, H. Bruining, M. Heck, J. Rost, and N. Van Leeuwen. 1995. Food initiated outbreak of methicillin-resistant Staphylococcus aureus analyzed by pheno and genotyping. J. Clin. Microbiol. 33: $1121-1128$.

22. Kreausukon, K., A. Fetsch, B. Kraushaar, K. Alt, K. Müller, V. Krömker, K. H. Zessin, A. Käsbohrer, and B. A. Tenhagen. 2012. Prevalence, antimicrobial resistance and molecular characterization of methicillin-resistant Staphylococcus aureus from bulk tank milk of dairy herds. J. Dairy Sci. 95:4382-4388.

23. LeJeune, J. T., and P. J. R. Schultz. 2009. Unpasteurized milk: a continued public health threat. Clin. Infect. Dis. 48:93-100.

24. Lim, S. K., H. M. Nam, G. C. Jang, H. S. Lee, S. C. Jung, and T. S. Kim. 2013. Transmission and persistence of methicillin-resistant Staphylococcus aureus in milk, environment, and workers in dairy cattle farms. Foodborne Pathog. Dis. 10:731-736.

25. Lina, G., Y. P. Mont, F. Godail-Gamot, M. Le Bes, M. O. Peter, V. Gauduchon, F. Vandenesch, and J. Etienne. 1999. Involvement of Panton-Valentine leukocidin-producing Staphylococcus aureus in primary skin infections and pneumonia. Clin. Infect. Dis. 29:1128-1132.

26. Linage, B., J. M. Rodríguez-Calleja, A. Otero, M. L. García-López, and J. A. Santos. 2012. Characterization of coagulase-positive staphylococci isolated from tank and silo ewe milk. J. Dairy Sci. 95:1639-1644.

27. McKay, A. M. 2008. Antimicrobial resistance and heat sensitivity of oxacillin-resistant, mecA-positive Staphylococcus spp. from unpasteurized milk. J. Food Prot. 71:186-190. 
28. Mehrotra, M., G. Wang, and W. M. Johnson. 2000. Multiplex PCR for detection of genes for Staphylococcus aureus enterotoxins, exfoliative toxins, toxic shock syndrome toxin 1, and methicillin resistance. J. Clin. Microbiol. 38:1032-1035.

29. Neder, V., V. R. Canavesio, and L. F. Calvinho. 2011. Presence of enterotoxigenic Staphylococcus aureus in bulk tank milk from Argentine dairy farms. Rev. Argent. Microbiol. 43:104-106.

30. Normanno, G., M. Corrente, G. La Salandra, A. Dambrosio, N. C. Quaglia, A. Parisi, G. Greco, A. L. Bellacicco, S. Virgilio, and G. V. Celano. 2007. Methicillin-resistant Staphylococcus aureus (MRSA) in food of animal origin product in Italy. Int. J. Food Microbiol. 117: 219-222.

31. Normanno, G., A. Firinu, S. Virgilio, G. Mula, A. Dambrosio, A. Poggiu, L. Decastelli, R. Mioni, S. Scuota, G. Bolzoni, E. Di Giannatale, A. P. Salinetti, G. La Salandra, M. Bartoli, F. Zuccon, T. Prino, S. Sias, A. Parisi, N. C. Quaglia, and G. V. Celano. 2005. Coagulase-positive staphylococci and Staphylococcus aureus in food products marketed in Italy. Int. J. Food Microbiol. 15:73-79.

32. Omoe, K., D. L. Hu, H. K. Ono, S. Shimizu, H. Takahashi-Omoe, A. Nakane, T. Uchiyama, K. Shinagawa, and K. Imanishi. 2013. Emetic potentials of newly identified staphylococcal enterotoxin-like toxins. Infect. Immun. 81:3627-3631.

33. Ortega, E., H. Abriouel, R. Lucas, and A. Gálvez. 2010. Multiple roles of Staphylococcus aureus enterotoxins: pathogenicity, superantigenic activity, and correlation to antibiotic resistance. Toxins 2:2117-2131.

34. Paterson, G. K., J. Larsen, E. M. Harrison, A. R. Larsen, F. J. Morgan, J. S. Peacock, J. Parkhill, R. N. Zadoks, and M. A. Holmes. 2012. First detection of livestock-associated methicillin-resistan
Staphylococcus aureus CC398 in bulk tank milk in the United Kingdom. Euro Surveill. 17:20337.

35. Paterson, G. K., F. J. Morgan, E. M. Harrison, E. J. Cartwright, M. E. Török, R. N. Zadoks, J. Parkhill, S. J. Peacock, and M. A. Holmes. 2014. Prevalence and characterization of human mecC methicillinresistant Staphylococcus aureus isolates in England. J. Antimicrob. Chemother. 69:907-910.

36. Shanehbandi, D., B. Baradaran, S. Sadigh-Eteghad, and H. Zarredar. 2014. Occurrence of methicillin resistant and enterotoxigenic Staphylococcus aureus in traditional cheeses in the North West of Iran. ISRN Microbiol. 2014:129580.

37. Tsegmed, U., G. Normanno, M. Pringle, and K. Krovacek. 2007. Occurrence of enterotoxic Staphylococcus aureus in raw milk from yaks and cattle in Mongolia. J. Food Prot. 70:1726-1729.

38. Türkyılmaz, S., S. Tekbıyık, E. Oryasin, and B. Bozdogan. 2010. Molecular epidemiology and antimicrobial resistance mechanisms of methicillin-resistant Staphylococcus aureus isolated from bovine milk. Zoonoses Public Health 57:197-203.

39. Yamamoto, T., A. Nishiyama, T. Takano, S. Yabe, W. Higuchi, O. Razvina, and D. Shi. 2010. Community-acquired methicillin-resistant Staphylococcus aureus: community transmission, pathogenesis and drug resistance. J. Infect. Chemother. 16:225-254.

40. Yilmaz, G., K. Aydin, S. Iskender, and R. K. I. Caylan. 2007. Detection and prevalence of inducible clindamycin resistance in staphylococci. J. Med. Microbiol. 56:342-345.

41. Zouharova, M., and D. Rysanek. 2008. Multiplex PCR and RPLA identification of Staphylococcus aureus enterotoxigenic strains from bulk tank milk. Zoonoses Public Health 55:313-319. 